(REVIEW ARTICLE)

\title{
The significance and role of various soft skills in professional life
}

\author{
Vinay Kumar Pandey ${ }^{1,{ }^{*}}$ and Sarika Shukla ${ }^{2}$ \\ ${ }^{1}$ Assistant Professor, Training Department, Axis Institute of Planning \& Management. Kanpur, Uttar Pradesh, India. \\ ${ }^{2}$ Assistant Professor, Training Department, Axis Institute of Planning \& Management. Kanpur, Uttar Pradesh, India.
}

Publication history: Received on 15 November 2020; revised on 28 November 2020; accepted on 02 December 2020

Article DOI: https://doi.org/10.30574/wjarr.2020.8.3.0453

\begin{abstract}
Soft skills are the new demand of HRs in all the corporate and educational organizations. As it includes the behavioral, interpersonal, communication, leadership, problem solving, managerial and other characteristics traits of personality. These are the skills which represents an organized and well-mannered reflection of human. Previously soft skills were found understood but now as population is increasing, it is decreasing the employability skills and so the job opportunities. People are busy in collecting degrees and experience certificates of various jobs and they have underestimated behavioral and social skills. Such skills have now become the most expected skills in each and every interview as well as in professional working. This paper will help professionals to understand the importance and significance of learning these soft skills.
\end{abstract}

Keywords: Soft skills; Communication; Job; Employability skills; Training; Professional

\section{Introduction}

Soft Skills function very important in the professional life. Soft Skills are combination of personal's traits, interpersonal skills, communication skills etc. When we talk about professional life; survival can be easy by adopting both hard \& Soft Skills which can give positive contribution to the company's business. A person's attitude, work ethic \& communication skills create an impression on the employer \& customers. See, on whole Soft Skills are important not only in professional but also in personal lives as well. If we notice the requirement of Corporates, we will find that Soft Skills are more in demand as it can be practiced over the time unlike Hard Skills which can be incorporated during college days. From screening of Resumes to Final PI round, Soft Skills has been proved equally important as technical skills. Soft Skills are used to describe our attitude towards work \& other people. In Industry, employer look for candidate with a story, work ethic, who can perform their work effectively and efficiently \& who are focused, organized \& has leadership skills. As corporate world is not only limited up to the company. It generates healthy relationship with the authorities and clients which will surely lead to an optimistic environment in the workplace [1].

\section{Need of soft skills in corporates}

Gone are the days when only Technical Skills were required for the job how to express these hard Skills, special skills I.e. people skills are in need. These people Skills will uplift a person's candidature. Technical skills are always incomplete without soft skill Soft Skills. Moreover, only technical skills will not be sufficient for conflict management among team members. For better communication co-worker would need Soft Skills. Soft Skills are now mostly preferred before technical skills \& they help in performing better in the corporate. Let's be acquainted with few Soft Skills which are considered to be beneficial in corporate world [2].

\footnotetext{
${ }^{*}$ Corresponding author: Vinay Kumar Pandey; ORCID: 0000-0001-9818-5805; Email- vinaypandey794@gmail.com Assistant Professor, Axis Institute of Planning \& Management, Kanpur, Uttar Pradesh, India. 


\subsection{Communication Skills}

Communication Skills indicate how you communicate with customer, colleagues, employers \& with everyone linked to the company. The one who has good communication will also be good in listening skills, Communication in public speaking, written communication, non-verbal communication, presentation skills. A small mistake in communication can lead to unpredictable loss of company and to the employee as well. So, while communicating we need to get the inside touch of each and every word we speak and write.

\subsection{Leadership Skills}

Leadership skills define a candidate's ability to lead a team, make decision, take responsibility \& work for the benefits of team \& company. Leadership is that skill which employer look for when hiring low rank to higher rank designation. This skill can be found in a candidate with a huge level of acceptance of responsibilities. Working in a team is a remarkable quality of a good leader. Leadership includes conflict management \& resolving, decision making, team management etc.

\subsection{Team Work}

Apart from the requirements of the various vacancies, it is clearly observed that every sector needs a candidate to work in a team and takes care of certain tasks and follow-ups which proves team work is one of the most essential soft skill of corporates. Team work has social, interpersonal and networking skills etc. It also represents your efforts in achieving a mutual goal as a team member.

\subsection{Work Ethics}

Work ethnics can be understood as Soft Skills which expresses about a person how he does in a job i.e. how to bears responsibility \& it also shows how a candidate is loyal towards his/ her career the following qualities fall under work ethics- punctuality, being focused, organized, persistence etc.

\subsection{Adaptability}

In this rapidly changing environment, adaptability is a prerequisite Soft Skill. Adaptability always adds glory to an individual personality. Phrases which can express adaptability are, optimistic, calm etc.

\subsection{Time Management}

HR Manager prefers employee who can use time effectively \& wisely. Time management skills needed by every employee because it increases productivity of the organization goal setting, planning, prioritizing, delegation can be used boost time management skills.

\subsection{Behavioral skills}

Whenever an employee works in multinational or small level company then its his /her keen responsibility to behave in a certain professional way because the performance and other achievements will not support you if you don't behave properly. For example, if we can understand the prospective of the person talking in front of us then we can react accordingly. The point is how are we reacting on it will show our thought process and level of understanding.

\section{Ignorance of nontechnical skills}

As we know that it this technical era people are technically savvy \& specially technocrats are sharpening their technical skills \& in this race Soft Skills are being ignored. However, in current scenario corporates with high demand for technical savvy employee many industries are losing these employees with less fundamental skills. Soft skills are not only limited up to resume building \& job seeking but it has acquired essential part in the form of working in team, problem solving skills \& critical thinking. It has been observed in many academic institutions that some technical faculty member often ignores such people skill which created a bad influence on pupils. Considering Soft Skills, an essential tool, very employee is now expected to coordinate with teams, delegate role in respective projects, in setting deadlines, in scaling problems etc. In fact, many surveys have proved that equally or more important than technical skills. According to LinkedIn. 58\% of HR Manager believe that lacking Soft Skills is just like limiting companies' productivity. There is a misconception among people that Soft Skills are that which can be naturally grown over the time but these skills can be 
developed as if somebody who is in the habit of coming late to office will not immediately learn time management on regular basis that's why it is said that Soft Skills glorifies Hard Skills. So, don't ignore them learn \& practice them for adding glitters in your career [3].

\section{Different attributes of personal skills}

The importance of soft skills is completely known to all of us and it is increasing every single day. Following table contains the list of certain qualities which will justify it in a simple way. Although there are many soft skills but here, we have mentioned few importance skills which one should definitely learn if they are targeting to get into an organizational culture [4].

Table 1 List of few most dominant soft skills.

\begin{tabular}{|l|l|}
\hline \multicolumn{2}{|c|}{ List of Some Important Soft Skills } \\
\hline Common Sense & Body Language \\
\hline Cooperation \&Team skills & Responsibility \\
\hline Active listening & Punctuality \\
\hline Dressing sense & Creative thinking skills \\
\hline Intrapersonal skills & Decision Making \\
\hline Time Management & Willingness to learn \\
\hline Problem Solving Ability & Leadership skills \\
\hline Project Management & Public Relations \\
\hline Negotiating skills & Work ethics \\
\hline Good attitude & Initiative \\
\hline Etiquette \& Manners & Presentation Skills \\
\hline
\end{tabular}

\section{Importance and future of soft skills}

As the need of such skills is increasing to get hired in different organizations so candidates have started opting these skills. Many educational institutions like Axis Colleges, Kanpur has started special classes as they have realized long ago that this will be the need of time in upcoming future. Management has hired qualified and certified trainers to deliver training lectures of soft skills. They are also working hard to train students in interview skills. Interview skills training is the only option left to enhance students in regards to reach new heights of placements. Depending on the requirements of different positions everyone is putting efforts to enhance and groom their personality because seeing the development of your personality from a normal person to a professional is most beautiful thing in life.

\section{Conclusion}

Professionalism is not something which can be learnt just by seeing others but it can be learnt through various training programs and also by raising your keen to learn attitude. Professional skills like communication, dressing sense and enhances your personality in a positive manner. Getting trained in these life skills is really a new trend but it is worth learning for. If students can be trained in these skills with the help of well qualified trainers then it will be helpful for them in acquiring success in professional life. In this paper we have focused the key elements of soft skills and their significance in life of a person working in corporates and other institutions. We have also discussed certain most required skills.

\section{Compliance with ethical standards}

\section{Acknowledgments}


The authors would like to acknowledge all of those who contributed to this work.

\section{Disclosure of conflict of interest}

The authors declared no conflicts of interest.

\section{References}

[1] Anju A. A Holistic Approach to Soft Skills Training. IUP Journal of Soft Skills. 2009; 3(1): 7-11.

[2] S Vasanthakumari. Soft skills and its application in work place. World Journal of Advanced Research and Reviews. 2019; 3(2): 66-72.

[3] Dennis R Laker, Jimmy LP. The differences between hard and soft skills and their relative impact on training transfer. Human Resource Development Quarterly. 2011; 22(1): 111-122.

[4] Dharmarajan PV, Pachigalla R, Lanka K. The Significance of Inculcating Soft Skills in Students in the Process of Teaching Hard Skills. Vol.I / Issue II /Sept-Nov, 2012/209.

\section{Authors Short Biography}

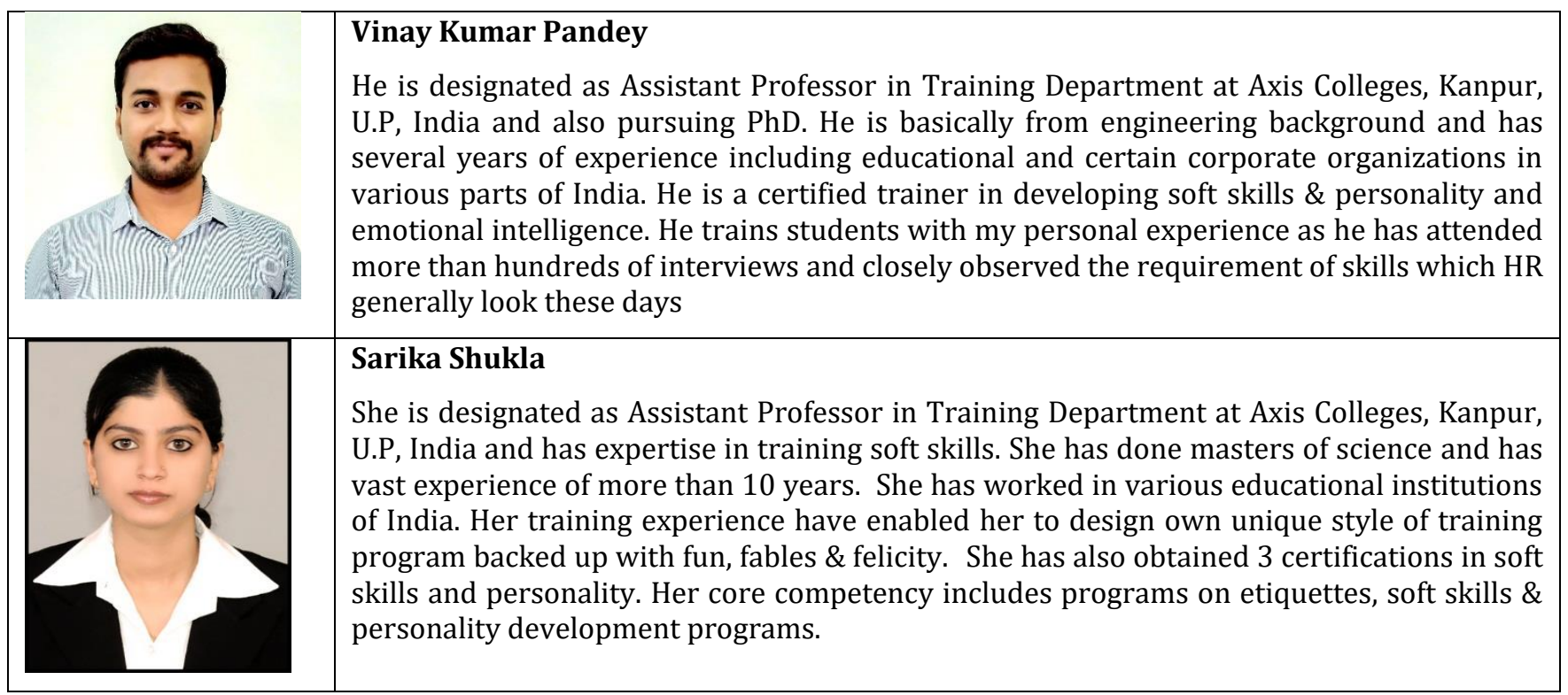

